\title{
Relationships between blood pressure and measures of dietary energy intake, physical fitness, and physical activity in Australian children aged 11-12 years
}

\author{
David A Jenner, Robert Vandongen, Lawrence J Beilin
}

\begin{abstract}
Study objective-The aim was to examine associations between blood pressure and dietary energy intake, physical activity, and physical fitness in Australian children.

Design-The study was a survey of year 7 children attending schools in metropolitan Perth.

Setting-Survey schools were located in suburbs representative of the range of socioeconomic strata in metropolitan Perth.

Participants-Data were obtained on 1311 out of 2045 eligible children (64\%). The sample included 681 boys and 630 girls. Mean age was 12.0 (SD 0.4 ) years.

Measurements and main resultsTriplicate blood pressure measurements were obtained using a Dinamap oscillometric recorder. Dietary energy intakes were computed from two week day $24 \mathrm{~h}$ records. Physical activity was assessed using questionnaires. Physical fitness was measured using a shuttle run test. Additional measurements included weight, height, and skinfold thickness at four sites. $A$ previous observation of an inverse relationship between diastolic blood pressure and dietary energy intake in boys was confirmed. There was evidence of an inverse relationship in girls but not in boys between blood pressure and physical activity. There was little evidence of relationships between blood pressure and physical fitness.
\end{abstract}

Conclusions-Compared with weight and body mass index, dietary energy intake and the chosen measures of physical activity and physical fitness are poor predictors of blood pressure in the population studied.

The potential value of long term approaches to hypertension control based on the prevention of high blood pressure in children is increasingly recognised. ${ }^{1}$ However, understanding of the determinants of blood pressure in childhood is incomplete and further research is needed to provide a basis for the development of effective prevention measures.

Relationships in children between blood pressure and age, body composition, and family history of high blood pressure have now been extensively explored and documented in a number of epidemiological studies; blood pressure has been shown to increase with age ${ }^{23}$ and body size, ${ }^{4-7}$ and relatively high blood pressure has been observed in children from families with a history of high blood pressure. ${ }^{89}$ Relationships between blood pressure and body composition have been confirmed in experimental studies. ${ }^{1011}$ Relationships between blood pressure and environmental and lifestyle factors such as diet and physical activity have been less thoroughly investigated and results have been inconsistent.

In an earlier study of nine year old children, ${ }^{12}$ we observed a negative relationship between diastolic blood pressure and dietary energy intake in boys and speculated that this may have been a reflection of associations of both variables with physical activity. Dietary energy intake is influenced by physical activity ${ }^{13}$ and has even been proposed as an indirect measure of the latter. ${ }^{14}$ In a number of studies of children, blood pressure has been shown to be related to measures of physical activity and physical fitness (sometimes used as a surrogate measure of physical activity), ${ }^{15-19}$ although in other studies, such relationships were undetectable. ${ }^{20} 21$

In this paper we describe the relationships between blood pressure and measures of dietary energy intake, physical activity, and physical fitness in a cohort of Australian children aged 11-12 years. We confirm our earlier observation ${ }^{12}$ of an inverse relationship between diastolic blood pressure and dietary energy intake in this cohort and test the hypotheses that blood pressure is inversely related to physical fitness and to habitual level of physical activity.

\section{Methods}

POPULATION SAMPLE

The target population comprised all children enrolled in year 7 classes in 27 government primary schools which had participated in an earlier survey in $1985,{ }^{12} 22$ together with those children who had previously participated but who had subsequently moved to other schools. The 27 original schools were located in suburbs representative of the range of socioeconomic strata in metropolitan Perth. The parents of each student were sent letters requesting permission for the student's participation.

\section{SURVEY PROCEDURES}

Examinations were carried out in the schools between April and August 1988. Blood pressure and anthropometric data were collected on the same day and diet and physical fitness data were collected on subsequent days, usually in the same week.

Dinamap $1846 \mathrm{SX} / \mathrm{P}$ oscillometric recorders were used for all blood pressure measurements. The operation principles and performance of the 
earlier Dinamap $845 \mathrm{XT}$ model in this series have previously been described. ${ }^{23} 24$ However, the latter model is now obsolete and there is relatively little similar information available for the newer Dinamap 1846 SX/P. Our own observations indicate a high degree of correlation between measurements obtained with the two models but a systematic difference of 3-6 $\mathrm{mm} \mathrm{Hg}$ (the 1846 $\mathrm{SX} / \mathrm{P}$ giving lower readings) between measurements in the same subject.

Each child arriving at the blood pressure measurement station sat down and was given a brief explanation of the measurement procedure by the research nurse. The nurse visually estimated the child's upper arm circumference and choose a Dinamap cuff of appropriate size from a range of four different sizes: small child (approximate limb circumference $10-19 \mathrm{~cm}$ ), child $(18-26 \mathrm{~cm})$, adult $(25-35 \mathrm{~cm})$, and large adult $(33-47 \mathrm{~cm})$. The match between cuff and arm size was checked using the Dinamap cuff marking system and, if necessary, a larger or smaller cuff was substituted. The operation and feel of the device was demonstrated to the child by means of a dummy set of readings. The child was then encouraged to sit quietly for five minutes after which time three further sets of readings were taken at one minute intervals. All measurements were made on the right arm with the arm supported on a table. Averages of the three readings were later computed for data analysis. Overall, $86^{\circ}{ }_{0}$ of measurements were carried out using Dinamap child cuffs (including measurements in two children made with the small child cuff) and $14^{\circ}{ }_{0}$ of measurements were obtained using Dinamap adult cuffs (including measurements in one child made with the large adult cuff). Whincup and colleagues ${ }^{25}$ have recently demonstrated an effect of cuff bladder size on blood pressure measurements in children which is independent of the effects of arm circumference. In their paper they show that the use of adult cuffs leads to underestimation of blood pressure. They recommended standardising results to a single cuff size. Using similar methods we have estimated the decrements in blood pressure associated with the use of the adult cuff to be $6.7 / 2.9 \mathrm{~mm} \mathrm{Hg}$ in girls and $6.5 / 1.8 \mathrm{~mm} \mathrm{Hg}$ in boys. Accordingly, all blood pressure measurements were standardised to the child cuff by adding these amounts to measurements made with the adult cuff.

Body composition measures included height, weight, body mass index $\left(\mathrm{kg} / \mathrm{m}^{2}\right)$, biceps, triceps, subscapular, and suprailiac skinfold thicknesses, and waist and hip girths. Triplicate measurements of skinfold thickness and girths were made at each site using standard techniques ${ }^{26} 27$ and averages were later calculated for use in data analyses.

Dietary energy intakes were assessed using a previously validated method based on two weekday $24 \mathrm{~h}$ diet records. ${ }^{28}$ Average energy intake over the two $24 \mathrm{~h}$ periods was computed for each subject.

Physical fitness was measured using a $20 \mathrm{~m}$ shuttle run test. ${ }^{29}$ This is a field test of aerobic endurance which has been shown to correlate well with treadmill and bicycle ergometer reference tests of physical fitness in children ${ }^{30} 31$ and adults. ${ }^{32}$ The length of time a subject is able to keep pace with a tape recorded signal can be used without conversion as a relative measure of physical fitness. Tests were conducted with groups of up to 15 children on tarmac surfaces using a fixed protocol.

Information on physical activity was collected using questionnaires competed by children and school staff. For each day of the week including weekend days children were asked to indicate the amount of time they usually spent doing out of school exercise or sports and the main type of exercise or sport concerned. The number of days per week on which they usually engaged in exercise or sport for at least one hour was used as a measure of the extent of out of school physical activity. The extent of in school physical activity was assessed by means of a questionnaire to school principals (27 main schools only). The total time per week scheduled for organised physical activity (including daily fitness, physical education, and sport) was computed for each school and each child was assigned to either a "low in school activity" group if his/her school fell on or below the median (a total of 150 minutes scheduled physical activity per week) or a "high in school activity" group if his/her school fell above this median value.

Additional data included the outside shade temperature in ${ }^{\circ} \mathrm{C}$ at the time of blood pressure and socioeconomic status. Each postcode in Australia has been assigned a relative socioeconomic status rating by the Australian Bureau of Statistics based on census data obtained in $1981 .{ }^{33}$ Ratings typically range between 40 and 70 on a continuous scale. The rating on this scale applying to the child's home address was used directly as a measure of socioeconomic status.

\section{STATISTICAL METHODS}

Distributions of systolic and diastolic blood pressure were examined and found to be approximately normal. In exploratory analysis of relationships between blood pressure and single independent variables, relationships with categorical variables were examined using $t$ tests and one way analysis of variance. Relationships with continuous independent variables were examined using Pearson correlation and one way analysis of variance after breaking down the continuous independent variable into quartiles or other logical categories.

Variables identified a priori as potential determinants of blood pressure in children and variables identified from the data as being related to blood pressure in this sample were then entered in combination in multiple regression analyses, with blood pressure as the dependent variable. After the entry of first order terms, quadratic and interaction terms were tested to see if they made any statistically significant additional contribution to explained variance in blood pressure. Backward elimination of variables was then used to restrict the variables in the final regression equation to those contributing significantly to explained variance in blood pressure. Finally, the relative contributions of these variables to explained variance in blood pressure was examined using a stepwise entry method. 
Table I Summary statistics relating to the study sample
Table II Blood pressure $(B P)$ in boys and girls according to dietary energy intake

\section{Results}

CHARACTERISTICS OF THE STUDY SAMPLE

A total of 2045 children were on record as having participated in 1985 and/or were on the year 7 class rolls of the main schools. Of these, 146 $(7 \cdot 1 \%)$ could not be traced, and a further 87 $(4.3 \%)$ were traced to remote lcoations and were excluded from the study. Consent forms were sent to parents of the remaining 1812 children Consent was received in $1348(74 \%)$ and refused in 233 cases $(13 \%)$. No reply was received in 231 cases $(13 \%)$. Complete blood pressure and body composition data were obtained in 1312 cases $(681$ boys and 631 girls). Data relating to one girl with retarded growth were omitted from statistical analyses. Summary statistics of selected measurements obtained during the study are shown in table I.

\begin{tabular}{|c|c|c|c|c|}
\hline & \multicolumn{2}{|c|}{$\begin{array}{l}\text { Boys } \\
(n=681)\end{array}$} & \multicolumn{2}{|c|}{$\begin{array}{l}\text { Girls } \\
(n=630)\end{array}$} \\
\hline & Mean & $S D$ & Mean & $S D$ \\
\hline Age (years) & $12 \cdot 0$ & 0.4 & $12 \cdot 0$ & 0.4 \\
\hline Height $(\mathrm{m})$ & 1.49 & 0.07 & 1.50 & 0.07 \\
\hline Weight $(\mathbf{k g})$ & 42.0 & $7 \cdot 9$ & $42 \cdot 9$ & $8 \cdot 2$ \\
\hline $\mathrm{BMI}\left(\mathrm{kg} / \mathrm{m}^{2}\right)$ & $18 \cdot 2$ & 2.5 & 18.9 & $2 \cdot 8$ \\
\hline Sum of four skinfolds (mm) & $33 \cdot 7$ & $17 \cdot 1$ & $40 \cdot 9$ & $17 \cdot 7$ \\
\hline Systolic BP $(\mathrm{mm} \mathrm{Hg})^{\star}$ & $115 \cdot 4$ & $9 \cdot 8$ & $114 \cdot 6$ & $9 \cdot 6$ \\
\hline Diastolic BP $(\mathrm{mm} \mathrm{Hg})$ * & $66 \cdot 9$ & 6.9 & $66 \cdot 7$ & $6 \cdot 4$ \\
\hline
\end{tabular}

BLOOD PRESSURE AND DIETARY ENERGY INTAKE

Complete diet record data were available for 626 boys $(92 \%)$ and 589 girls (93\%). Dietary energy intakes were roughly normally distributed. Mean values were 8.6 (SD 2.3) MJ and 7.5 (2.1) MJ for boys and girls respectively.

A weak negative correlation was observed between diastolic blood pressure and dietary energy intake in boys $(r=-0.12, p<0.01)$. Correlations between diastolic blood pressure and energy intake in girls and between systolic blood pressure and energy intake in both boys and girls were not statistically significant. Mean levels of blood pressure in boys and girls in energy intake quartiles are shown in table II. Among the boys, mean diastolic blood pressure was low in the top quartile relative to the other three quartiles.

BLOOD PRESSURE AND PHYSICAL FITNESS

The $20 \mathrm{~m}$ shuttle run data were available for 565 boys $(83 \%)$ and 527 girls ( $84 \%)$. Run times were roughly normally distributed both for boys and girls. Ranges of times were $2 \cdot 2-12 \cdot 3 \mathrm{~min}$ for boys and 1.9-10.7 min for girls. Mean times were $7 \cdot 7$

\begin{tabular}{|c|c|c|c|}
\hline $\begin{array}{l}\text { Energy } \\
(M \mathcal{M})\end{array}$ & $n$ & $\begin{array}{l}\text { Systolic BP } \\
\text { mean }(95 \% \text { CI) }\end{array}$ & $\begin{array}{l}\text { Diastolic } B P \\
\text { mean }(95 \% C I)\end{array}$ \\
\hline $\begin{array}{l}-7 \cdot 0 \\
7 \cdot 0-8 \cdot 4 \\
8 \cdot 4-9 \cdot 9 \\
9 \cdot 9\end{array}$ & $\begin{array}{l}159 \\
161 \\
155 \\
151\end{array}$ & $\begin{array}{cc} & \text { Boys } \\
117 \cdot 2 & (115 \cdot 4,118.9) \\
117.0 & (115 \cdot 5,118 \cdot 5) \\
115.5 & (114 \cdot 1,116.8) \\
115.9 & (114 \cdot 2,117 \cdot 6)\end{array}$ & $\begin{array}{ll}68 \cdot 0 & (66 \cdot 9,69 \cdot 0) \\
67 \cdot 5 & (66 \cdot 5,68 \cdot 6) \\
67 \cdot 5 & (66 \cdot 5,68 \cdot 6) \\
65 \cdot 9 & (64 \cdot 7,67 \cdot 1)\end{array}$ \\
\hline ANOVA & & $F=1.09, p=0.35$ & $F=2 \cdot 78, p=0.04$ \\
\hline $\begin{array}{l}-6 \cdot 0 \\
6 \cdot 0-7 \cdot 3 \\
7 \cdot 3-8 \cdot 8 \\
8 \cdot 8-\end{array}$ & $\begin{array}{l}151 \\
144 \\
155 \\
139\end{array}$ & $\begin{array}{cc} & \text { Girls } \\
113 \cdot 8 & (112 \cdot 4,115 \cdot 3) \\
116 \cdot 3 & (114 \cdot 4,118 \cdot 2) \\
115 \cdot 7 & (114 \cdot 2,117 \cdot 1) \\
116 \cdot 7 & (115 \cdot 1,118 \cdot 3)\end{array}$ & $\begin{array}{ll}66.8 & (65 \cdot 8,67 \cdot 8) \\
67.6 & (66 \cdot 5,68 \cdot 7) \\
66.9 & (65 \cdot 9,68 \cdot 0) \\
67 \cdot 5 & (66 \cdot 5,68 \cdot 5)\end{array}$ \\
\hline ANOVA & & $F=2.52, p=0.06$ & $F=0.57, p=0.64$ \\
\hline
\end{tabular}

(2.0) min and $6.2(1.6)$ min for boys and girls respectively.

Blood pressure was not significantly correlated with run time in either boys or girls. Mean levels of blood pressure in boys and girls in run time quartiles are shown in table III. Blood pressure differences were modest. Girls with the highest

Table III Blood pressure (BP) in boys and girls according to $20 \mathrm{~m}$ shuttle run test time

\begin{tabular}{|c|c|c|c|}
\hline $\begin{array}{l}\text { Time } \\
\text { (mins) }\end{array}$ & $n$ & $\begin{array}{l}\text { Systolic BP } \\
\text { mean }\left(95^{\circ} C I\right)\end{array}$ & $\begin{array}{l}\text { Diastolic } B P \\
\text { mean }\left(95^{\circ}{ }_{o} C I\right)\end{array}$ \\
\hline $\begin{array}{l}-6 \cdot 2 \\
6 \cdot 2-7 \cdot 8 \\
7 \cdot 8-9 \cdot 2 \\
9 \cdot 2-\end{array}$ & $\begin{array}{l}144 \\
137 \\
143 \\
141\end{array}$ & $\begin{array}{cc} & \text { Boys } \\
116 \cdot 9 & (115 \cdot 1,118 \cdot 7) \\
115 \cdot 5 & (113 \cdot 9,117 \cdot 2) \\
116 \cdot 3 & (114 \cdot 8,117 \cdot 9) \\
116 \cdot 7 & (114 \cdot 9,118 \cdot 5)\end{array}$ & $\begin{array}{ll}67 \cdot 0 & (65 \cdot 9,68 \cdot 0) \\
66 \cdot 6 & (65 \cdot 4,67 \cdot 7) \\
67 \cdot 4 & (66 \cdot 1,68 \cdot 6) \\
67 \cdot 8 & (66 \cdot 7,69 \cdot 0)\end{array}$ \\
\hline ANOVA & & $F=0.49, p=0.69$ & $F=0.82, p=0.49$ \\
\hline $\begin{array}{l}-5 \cdot 0 \\
5 \cdot 0-6 \cdot 1 \\
6 \cdot 1-7 \cdot 3 \\
7 \cdot 3-\end{array}$ & $\begin{array}{l}133 \\
131 \\
128 \\
135\end{array}$ & $\begin{array}{cc} & \text { Girls } \\
115 \cdot 5 & (113 \cdot 5,117 \cdot 4) \\
116 \cdot 1 & (114 \cdot 5,117 \cdot 8) \\
117 \cdot 4 & (115 \cdot 7,119 \cdot 1) \\
113 \cdot 6 & (112 \cdot 1,115 \cdot 1)\end{array}$ & $\begin{array}{ll}66 \cdot 7 & (65 \cdot 6,67 \cdot 8) \\
67 \cdot 3 & (66 \cdot 2,68 \cdot 3) \\
67 \cdot 3 & (66 \cdot 1,68 \cdot 4) \\
66 \cdot 6 & (65 \cdot 7,67 \cdot 6)\end{array}$ \\
\hline ANOVA & & $F=3.27, p=0.02$ & $F=0.37, p=0.77$ \\
\hline
\end{tabular}

$\mathrm{CI}=$ confidence interval; ANOVA $=$ analysis of variance

run times had notably lower systolic blood pressure than their less fit counterparts. There was, however, no evidence of a progressive decrease in blood pressure from the least fit to the most fit girls.

\section{BLOOD PRESSURE AND PHYSICAL ACTIVITY}

Six hundred and forty three boys $(94.4 \%)$ and 574 girls $(91.1 \%)$ reported some out of school exercise or sport on at least one day of the week. Among the boys, the most commonly reported specific exercise or sport was football $(15 \%$ of all activities cited) followed by cycling $(11 \%)$ and basketball $(9 \%)$. Overall, however, non-specific exercise or sport ("playing" or "running around") was most common (23\% of all activities cited). Similarly, among the girls, non-specific exercise or sport was most common $(27 \%$ of all activities cited) followed by netball $(16 \%)$, cycling $(12 \%)$, and ballet/dance/gymnastics $(5 \%)$.

The number of physically active days per week was negatively correlated with diastolic blood pressure in girls $(r=0.13, p=0.001)$. In contrast, relationships with systolic blood pressure in girls and systolic and diastolic blood pressure in boys were non-significant. As indicated in table IV, there were only modest blood pressure differences between groups differing in extent of out of school physical activity during the week. Among the girls, those who reported the lowest number of days on which physical activity occurred had the highest diastolic blood pressure. There was no evidence of blood pressure differences between groups of boys and girls differing in terms of in school physical activity and no evidence of interactions between out of school and in school physical activity.

INTERRELATIONSHIPS BETWEEN DIETARY ENERGY INTAKE, PHYSICAL FITNESS, AND PHYSICAL ACTIVITY

The number of physically active days per week was significantly correlated with 20 m shuttle run time in boys $(r=0.19, p<0.001)$ and in girls $(r=0.20, p<0.001)$. Mean $20 \mathrm{~m}$ shuttle run time 
Table IV Blood pressure ( $B P$ ) in boys and girls differing in level of out of school physical activity

\begin{tabular}{|c|c|c|c|}
\hline $\begin{array}{l}\text { Number of } \\
\text { active days } \\
\text { per week }\end{array}$ & $n$ & $\begin{array}{l}\text { Systolic BP } \\
\text { mean }\left(95^{\circ}{ }_{0} C I\right)\end{array}$ & $\begin{array}{l}\text { Diastolic BP } \\
\text { mean }\left(95^{\circ}{ }_{0} C I\right)\end{array}$ \\
\hline $\begin{array}{l}0 \text { or } 1 \\
2 \text { or } 3 \\
4 \text { or } 5 \\
6 \text { or } 7\end{array}$ & $\begin{array}{r}77 \\
189 \\
168 \\
247\end{array}$ & $\begin{array}{cc} & \text { Boys } \\
115 \cdot 9 & (113 \cdot 7,118 \cdot 2) \\
117 \cdot 3 & (115 \cdot 9,118 \cdot 7) \\
117 \cdot 0 & (115 \cdot 4,118 \cdot 7) \\
115 \cdot 1 & (114 \cdot 0,116 \cdot 3)\end{array}$ & $\begin{array}{ll}66 \cdot 0 & (64 \cdot 2,67 \cdot 7) \\
67 \cdot 7 & (66 \cdot 8,68 \cdot 6) \\
67 \cdot 9 & (66 \cdot 9,69 \cdot 0) \\
66 \cdot 6 & (65 \cdot 7,67 \cdot 4)\end{array}$ \\
\hline ANOVA & & $F=2.14, p=0.09$ & $F=2.48, p=0.06$ \\
\hline $\begin{array}{l}0 \text { or } 1 \\
2 \text { or } 3 \\
4 \text { or } 5 \\
6 \text { or } 7\end{array}$ & $\begin{array}{l}122 \\
260 \\
125 \\
123\end{array}$ & $\begin{array}{cc} & \text { Girls } \\
117 \cdot 3 & (115 \cdot 2,119 \cdot 4) \\
115 \cdot 2 & (114 \cdot 1,116 \cdot 3) \\
114 \cdot 6 & (112 \cdot 9,116 \cdot 3) \\
115 \cdot 3 & (113 \cdot 6,117 \cdot 0)\end{array}$ & $\begin{array}{ll}68 \cdot 3 & (67 \cdot 2,69 \cdot 5) \\
67 \cdot 4 & (66 \cdot 7,68 \cdot 1) \\
65 \cdot 8 & (64 \cdot 6,66 \cdot 9) \\
66 \cdot 4 & (65 \cdot 3,67 \cdot 6)\end{array}$ \\
\hline ANOVA & & $F=1.80, p=0.14$ & $F=4.19, p=0.006$ \\
\hline
\end{tabular}

for boys reporting physical activity on six or seven days per week was significantly greater than the mean time in boys reporting physical activity on zero or one days per week, at $8 \cdot 0(0 \cdot 1) v 6 \cdot 8(0 \cdot 3)$ min. Equivalent mean times for girls were 6.4 $(0 \cdot 2) \mathrm{min}$ and $5 \cdot 7(0 \cdot 2) \mathrm{min}$ respectively.

Among the girls, dietary energy intake was positively correlated with both $20 \mathrm{~m}$ shuttle run time $(r=0.14, p=0.002)$ and number of physically active days per week ( $r=0.09$, $p=0.04)$. Among the boys, these relationships were not statistically significant.

\section{MULTIPLE REGRESSION ANALYSES OF BLOOD} PRESSURE

Complete data on blood pressure, body composition, physical fitness, physical activity, and dietary energy intake were available for 526 boys and 504 girls, and multiple regression analyses were restricted to these subsamples. The independent variables set included AGE (age in years), HT (height in cm), wT (weight in kg), BMI (body mass index), suM4 (the sum of biceps + triceps + subscapular + suprailiac skinfold thicknesses), wHR (waist/hip girth ratio), SES (socioeconomic status), TEMP (outside shade temperature in ${ }^{\circ} \mathrm{C}$ at the time of blood pressure measurement), ACTIVITY (usual number of days per week which include one hour or more of exercise or sport), FITNESS (time in minutes achieved in the $20 \mathrm{~m}$ shuttle run test), ENERGY (dietary energy intake in $\mathrm{MJ}$ ), and their respective quadratic terms. Final regression equations, including only those terms which made a statistically significant contribution to explained variance in blood pressure, were as follows:

Boys:

Systolic blood pressure $(\mathrm{mm} \mathrm{Hg})=$

$79.5+0.65 \times$ BMI $+0.25 \times$ HT $-2.4 \times$ ENERGY $+0 \cdot 11 \times$ ENERGY $^{2}$

Diastolic blood pressure $(\mathrm{mm} \mathrm{Hg})=$

$$
72 \cdot 1+1.2 \times \text { TEMP }-0.03 \times \text { TEMP }^{2}-0.78 \times \text { BMI }
$$$$
+0.09 \times \text { SUM } 4-0.32 \times \text { ENERGY }
$$

Girls:

Systolic blood pressure $(\mathrm{mm} \mathrm{Hg})=$

$86 \cdot 1+0.41 \times \mathrm{WT}+0.18 \times$ SES $+0.45 \times$ ENERGY

$-0.41 \times$ ACTIVITY

Diastolic blood pressure $(\mathrm{mm} \mathrm{Hg})=$

$37.6+1.9 \times$ AGE $+0.16 \times$ SES $-0.56 \times$ ACTIVITY

In the boys, $8 \cdot 6 \%$ of variance in systolic blood pressure was explained by BMI, HT, ENERGY, and ENERGY $^{2}$. BMI and HT contributed $4 \cdot 8 \%$ and $2 \cdot 1 \%$ respectively to explained variance and ENERGY and ENERGY ${ }^{2}$ together contributed a further $1 \cdot 7^{\circ}{ }_{0}$. Based on regression equation (1), an increment in dietary energy intake from $6 \mathrm{MJ}$ to $9 \mathrm{MJ}$ would be associated with a fall of $2.3 \mathrm{~mm} \mathrm{Hg}$ and an increment from $9 \mathrm{MJ}$ to $12 \mathrm{MJ}$ would be associated with a fall of $0.3 \mathrm{~mm} \mathrm{Hg}$.

In the girls, $12.5 \%$ of variance in systolic blood pressure was explained by WT, SES, ENERGY, and ACTIVITY, these four variables contributing $9.7^{\circ} \mathrm{o}$, $1.4 \%, 0.7 \%$, and $0.7 \%$ respectively to explained variance. Based on regression equation (3), an increase in the number of physically active days per week from zero to seven would be associated with a decrease in systolic blood pressure of $2.9 \mathrm{~mm} \mathrm{Hg}$. In contrast, the observed relationship with ENERGY was positive, with a predicted systolic blood pressure rise of $0.9 \mathrm{~mm} \mathrm{Hg}$ for every $2.1 \mathrm{MJ}$ (approximately one standard deviation) increase in dietary energy intake.

Of the diastolic blood pressure variance in boys, $6 \cdot 7^{\circ}$ was explained by TEMP, TEMP ${ }^{2}$, ENERGY, BMI, and SUM4. Together, TEMP, and TEMP ${ }^{2}$ contributed $3.2 \%$ to explained variance, while ENERGY, BMI and SUM4 contributed $1.4^{\circ}{ }_{0}, 1 \cdot 0^{\circ}{ }_{0}$, and $1 \cdot 1 \%$ respectively. Regression equation (2) predicts a fall of $0.7 \mathrm{~mm} \mathrm{Hg}$ associated with a 2.3 $\mathrm{MJ}$ increase (approximately one standard deviation) in dietary energy intake.

Of the diastolic blood pressure variance in girls, $6 \cdot 1^{\circ}$ o was explained by ACTIVITY, AGE, and SES. ACTIVITY $\left(2 \cdot 7^{\circ}\right)$ and SES $\left(2 \cdot 3^{\circ}{ }_{0}\right)$ were the main contributors, followed by AGE $\left(0 \cdot 9^{\circ}\right)$. Based on regression equation (4), an increase in the number of physically active days per week from 0 to 7 days would be associated with a decrease in diastolic blood pressure of $3.9 \mathrm{~mm} \mathrm{Hg}$.

\section{Discussion}

In summary, we observed an independent, inverse relationship between diastolic blood pressure and dietary energy intake in boys. There was no evidence of a similar relationship in girls. Blood pressure was inversely related to the questionnaire based measure of physical activity in girls but not in boys. Overall, the proportions of blood pressure variance explained by dietary energy intake and physical activity were modest. After adjustment for other variables in multiple regression analyses, no statistically significant relationships were observed between blood pressure and physical fitness in either sex.

It is important to consider whether biases may have been introduced as a result of measurement error. There are no grounds for suspecting that any of the measures used in this study were subject to systematic error. Given the scale of the study and the nature of the population sample some trade off was necessary between precision on the one hand and practicability on the other, and a degree of random measurement error is to be expected. Random error, in turn, causes bias towards the null, ie, underestimation of the strength of relationships.

Although the blood pressure measurement method, based on three consecutive readings taken after a five minute rest period, was relatively elaborate compared to some previous epidemiological studies of blood pressure in children, it 
clearly has limitations as a method for the measurement of "usual" blood pressure. Similarly, if a dietary assessment method based on two weekday $24 \mathrm{~h}$ diet records is used as a method of assessing "usual" dietary intake there will inevitably be some random error. Establishing the true validity and accuracy of methods such as these for the measurement of usual blood pressure and usual dietary intakes is effectively impossible. The best that can be achieved is a relative validation such as that carried out for the present dietary assessment method. ${ }^{28}$ Although the statistical relationships between blood pressure and dietary variables described in this paper may not truly reflect the strength of actual relationships in the population, we feel that the present measurement methods are sufficiently valid and accurate that important relationships are unlikely to have been missed.

Physical fitness measurements obtained using the $20 \mathrm{~m}$ shuttle run test have been shown to correlate well with measurements obtained using standard $\mathrm{VO}_{2}$ methods. ${ }^{30-32}$ In contrast to several previous studies, ${ }^{15-19}$ we failed to detect an inverse relationship between physical fitness and blood pressure in boys. Among the girls, those with the lowest shuttle run times had the lowest mean systolic blood pressure, but there was no evidence of a progressive decrease in blood pressure from the least fit to the most fit girls. Methods for determining physical fitness in previous studies varied and included a treadmill test, ${ }^{15}$ a step test, ${ }^{16}{ }^{17}$ and bicycle ergometer tests. ${ }^{18}{ }^{19}$ In most cases, authors supported their choice of fitness test with evidence of validity. It is conceivable that the $20 \mathrm{~m}$ shuttle run test and the tests used in other studies reflect different aspects of physical fitness while still correlating highly with $\mathrm{VO}_{2}$ max. There are grounds, for example, for expecting that children who are used to cycling will perform relatively well in a bicycle ergometer test and that children who are used to running will perform relatively well in a running test. The extent to which weight confounds relationships between physical fitness and blood pressure probably also varies between studies since weight affects performance in fitness tests to a varying degree. In this study, however, there was no consistent evidence of a relationship between blood pressure and physical fitness either before or after adjustment for weight. One possible explanation for the apparent discrepancy between this and previously published studies is that the actual relationship between physical fitness and blood pressure in children is weak and that, as a result of biases towards submission and publication of studies with positive results, an unrepresentative group of studies has been published.

In contrast to the measure of physical fitness, the measure of physical activity used here has not been validated and its accuracy as a measure of habitual level of physical activity remains to be determined. It is possible that differences in the accuracy of measurements of physical activity level in boys and girls may have contributed to the observed sex differences in relationships with blood pressure.

In spite of the lack of strong relationships between the measures of physical activity and dietary energy intake used in the present study, it is reasonable to assume, based on the laws of thermodynamics, that actual physical activity level is a determinant of actual dietary energy intake. In view of this and in view of the body of evidence of inverse relationships between blood pressure and measures of physical activity, the present observation of a positive regression relationship between systolic blood pressure and dietary energy intake in girls seems incongruous. The observed relationship was weak and it is conceivable that it was a chance result. Alternatively, it may indicate a complex role of energy intake in the data set. Once the hypothesised blood pressure variance due to variations in physical activity has been partially or completely "explained" by the variable ACTIVITY, the variable ENERGY may assume a different role in the data set. If, for example, other determinants of dietary energy intake such as basal metabolic rate are themselves directly related to blood pressure, the nature of the association between ENERGY and blood pressure may be influenced. Alternatively, total energy may be acting as a surrogate for some characteristic of diet with a prohypertensive effect.

Compared to dietary energy intake, physical activity and physical fitness, weight, and body mass index were rather better predictors of systolic blood pressure. In boys, an increment in body mass index of $2.5 \mathrm{~kg} / \mathrm{m}^{2}$ (approximately one standard deviation) was associated with an increment in systolic blood pressure of $1.6 \mathrm{~mm} \mathrm{Hg}$. In girls, an increment in weight of $8 \mathrm{~kg}$ (approximately one standard deviation) was associated with an increment in systolic blood pressure of $3.3 \mathrm{~mm} \mathrm{Hg}$. A complex relationship was observed between diastolic blood pressure and body composition in boys in which diastolic blood pressure was negatively related to body mass index and positively related to the sum of four skinfold thicknesses, each of which contributed around $1^{\circ}$ 。 to explained diastolic blood pressure variance. These data suggest that diastolic blood pressure is related more to body composition than to overall body size; boys in a certain body mass index range with low fat/muscle ratios would be predicted to have lower diastolic blood pressure than boys in the same body mass index range with high fat/muscle ratios. Relationships in girls between diastolic blood pressure and body mass index and sum of skinfolds were both positive but were somewhat weaker, failing to reach statistical significance. Overall, however, the strengths of the associations observed in the present study and similar data from other studies ${ }^{4-7}$ indicate that body size and body fatness are important determinants of blood pressure in children. There is already some evidence that reductions in fatness in children are accompanied by reductions in blood pressure. ${ }^{1011}$ In view of this and of the evidence from other studies of an association between obesity and high blood lipid levels, ${ }^{34}{ }^{35}$ overweight/obesity is clearly an appropriate choice as a primary target for any cardiovascular disease risk reduction intervention.

Other variables related to blood pressure in this study included temperature, age, and socioeconomic status. A curvilinear relationship was observed in boys between diastolic blood pressure and outside shade temperature with a decrease of $1.7 \mathrm{~mm} \mathrm{Hg}$ associated with an increase in outside temperature from $15^{\circ} \mathrm{C}$ to $25^{\circ} \mathrm{C}$ and a decrease of $4.7 \mathrm{~mm} \mathrm{Hg}$ associated with an increase in outside 
temperature from $20^{\circ} \mathrm{C}$ to $30^{\circ} \mathrm{C}$. An inverse, linear relationship between diastolic blood pressure and environmental temperature was observed in an earlier study of the same cohort. ${ }^{22}$ The lack of a negative relationship between blood pressure and environmental temperature in girls may reflect their relatively greater levels of body fat; in the earlier study ${ }^{22}$ and in at least one previous study, ${ }^{36}$ the strength of relationship between blood pressure and temperature was related to body fatness.

A weak independent, positive relationship was observed between diastolic blood pressure and age in girls. Based on previous studies ${ }^{2}{ }^{3}$ such a relationship is not unexpected. The particularly narrow age range of the sample probably accounts for the failure to observe a similar relationship in boys and relationships between age and systolic blood pressure in boys and girls.

Independent relationships were observed between socioeconomic status and both systolic and diastolic blood pressure in girls in the present study. Based on the regression equations, and all else being equal, girls living in a typical high socioeconomic status suburb with a socioeconomic status index of 65 would be expected to have a systolic blood pressure level $3.6 \mathrm{~mm} \mathrm{Hg}$ higher and a diastolic blood pressure level $3.2 \mathrm{~mm} \mathrm{Hg}$ higher than girls living in a typical low socioeconomic status suburb with an index of 45 . These results conflict with previous findings of higher blood pressure in lower socioeconomic status groups ${ }^{37} 38$ and the explanation for this is unclear. Relationships between blood pressure and socioeconomic status in boys in this study were relatively weak.

The results of this study indicate that dietary energy intake, physical activity, and physical fitness are, at best, only weakly related to blood pressure in Australian children. This does not, however, rule out the possiblity that exercise and other aspects of childhood lifestyle play a major role in determining blood pressure in adulthood. Prospective or retrospective cohort studies will be needed to address this issue.

The authors would like to thank Diana Dunbar, Sarah Henzell, and Jan Watt for assisting with data collection. The study was supported by a grant from the TVW Telethon Foundation.

1 WHO. Prevention in childhood and youth of adult cardiovascular disease: time for action. (WHO Tech Rep Series 792.) Geneva: WHO, 1990.

2 Task Force on Blood Pressure Control in Children. Report of the Second Task Force on Blood Pressure Control in Children-1987. Pediatrics 1987; 79: 1-25.

3 Jureidini KF, Baghurst PA, Hogg RJ, et al. Blood pressure in schoolchildren measured under standardized conditions. Med F Aust 1988; 149: 132-4.

4 Voors AW, Webber LS, Frerichs RR, Berenson GS. Body height and body mass as determinants of basal blood pressure in children: the Bogalusa Heart Study. $A m \mathcal{F}$ Epidemiol 1977; 106: 101-8.

5 Lauer RM, Burns TL, Clarke WR. Assessing children's blood pressure: considerations of age and body size: the Muscatine Study. Pediatrics 1985; 75: 1081-90.

6 Prineas RJ, Gillum RF, Horibe H, et al. The Minneapolis children's blood pressure study. Part 2: multiple determinants of children's blood pressure. Hypertension 1980; 2: 24-8.

7 Otero ML, Sanchez RG, Claros NM, et al. Relationship of blood pressure levels to height, weight and sodium and potassium excretion in Spanish children $f$ Hypertens 1985 3 (suppl 3): S91-3.

8 Biron P, Mongeau JG. Familial aggregation of blood pressure and its components. Pediatr Clin North Am 1978;
25: 29 .
9 van Hooft IM, Hofman A, Grobbee DE, Valkenburg HA Change in blood pressure in offspring of parents with high or low blood pressure: the Dutch Hypertension and Offspring Study. 7 Hypertens 1988; 6 (suppl 4): S594-6.

10 Brownell KD, Kelman JH, Stunkard AJ. Treatment of obese children with and without their mothers: changes in weight and blood pressure. Pediatrics 1983; 71: 515-23.

11 Becque MD, Katch VL, Rocchini AP, Marks CR, Moorehead C. Coronary risk incidence of obese Pediatrics 1988; 81: 605-12.

12 Jenner DA, English DR, Vandongen R, et al. Diet and blood pressure in a 9-year-old Australian children. Am 7 Clin putr 1988; 47: 1052-9.

13 Willett W, Stampfer MJ. Total energy intake: implications for epidemiologic analyses. Am $\mathcal{F}$ Epidemiol 1986; 124 17-27.

14 Slattery ML, Jacobs DR, Nichaman MZ. An assessment of caloric intake as an indicator of physical activity. Prev Med 1989; 18: 444-51.

15 Fraser GE, Phillips RL, Harris R. Physical fitness and blood pressure in school children. Circulation 1983; 67: 405-12.

16 Panico S, Celentano E, Krogh V, et al. Physical activity and its relationship to blood pressure in school children. $\mathcal{F}$ Chron Dis 1987; 40: 925-30.

17 Hofman A, Walter HJ, Connelly PA, Vaughan RD. Blood pressure and physical fitness in children. Hypertension 1987; 9: 188-91.

18 Sallis JF, Patterson TL, Buono MJ, Nader PR. Relation of cardiovascular fitness and physical activity to cardiovascular disease risk factors in children and adults. $A m \mathcal{f}$ Epidemiol 1988; 127: 933-41.

19 Tell GS, Vellar OD. Physical fitness, physical activity and cardiovascular disease risk factors in adolescents: the Oslo cardiovascular disease risk factors in adolesce

20 Strazzulo P, Cappuccio FP, Trevisan M, et al. Leisure time physical activity and blood pressure in school children. $\mathrm{Am}$ f Epidemiol 1988; 127: 726-33.

21 Marti B, Vartiainen E. Relation between leisure time and cardiovascular risk factors among 15-years-olds in Eastern Finland. F Epidemiol Community Health 1989; 43: 228-33. 22 Jenner DA, English DR, Vandongen R, Beilin LJ, Armstrong BK, Dunbar D. Environmental temperature and blood pressure in 9-year-old Australian children. $\mathcal{f}$ Hypertens 1987; 5: 683-6.

23 Park MK, Menard SM. Accuracy of blood pressure measurement by the Dinamap monitor in infants and children. Pediatrics 1987; 79: 907-14.

24 Jenner DA, Beilin LJ, Vandongen R, De Klerk NH. A comparison of blood pressure measurements obtained with the Dinamap 845XT, the standard mercury sphygmomanometer and the London School of Hygiene device. Clin Exp Hypertens.A 1988; 10: 575-88.

25 Whincup PH, Cook DG, Shaper AG. Blood pressure measurement in children: the importance of cuff bladder measurement in children: the import
size. F Hypertens $1989 ; 7: 845-50$.

26 Weiner JS, Lourie JA. Human biology: a guide to field methods. Oxford: Blackwell, 1969.

27 US Department of Health, Education and Welfare. Body dimensions and proportions, white and negro children 6-11 years. Washington DC: DHEW Publication No (HRA) 75-1625, 1974

28 Jenner DA, Neylon K, Croft S, Beilin LJ, Vandongen R. A comparison of methods of dietary assessment in 12-yearold Australian children. Eur f Clin Nutr 1989; 10: 663-74.

29 Leger L, Lambert J, Goulet A, Rowan C, Dinelle Y. Aerobic capacity of Quebecois aged 6-17: the 20-metre shuttle run test with one minute stages. Can $\mathcal{F}$ Appl Sport $S_{c i} 1984 ; 9$. 64-9.

30 van Mechelen W, Hlobil H, Kemper HCG. Validation of two running tests as estimates of maximal aerobic power in children. Eur $\mathcal{f}$ Appl Physiol 1986; 55: 503-6.

31 Leger LA, Lambert J, Mercier D. Predicted $\mathrm{VO}_{2} \max$ and maximal speed for a multistage 20 -m shuttle run in 7000 maximal speed for a multistage 20-m shuttle run in 7000 Quebec

32 Leger LA, Lambert J. A maximal, multistage 20-m shuttle run test to predict $\mathrm{VO}_{2}$ max. Eur $\mathcal{F}$ Appl Physiol 1982; 49 $1-12$

33 Australian Bureau of Statistics, Statistical Methods Section. Construction of an indicator of socio-economic status. Information Paper No 15. Canberra: Australian Bureau of Statistics, 1986.

34 Smoak CG, Burke GL, Webber LS, Harsha DW, Srinivasan SR, Berenson GS. Relation of obesity to clustering of cardiovascular disease risk factors in children and youn adults: the Bogalusa Heart Study. Am $\mathcal{F}$ Epidemiol 1987; 125: 364-72.

35 Lauer RM, Lee J, Clarke WR. Factors affecting the relationship between childhood and adult cholesterol
levels: the Muscatine Study. Pediatrics 1988; 82: 309-18.

36 Brennan PJ, Greenberg G, Miall WE, Thompson SG Seasonal variation in arterial blood pressure. $B M \mathcal{F} 1982$; 285: $9191-23$.

37 Gillum RF, Prineas RJ, Gomex-Martin O, et al. Personality, behaviour, family environment, family socioeconomic status and hypertension risk factors in children. $₹$ Chron Dis 1985; 38: 187-94.

38 Dwyer T, Coonan W, Worsley A, Leitch D. Sex, social status and ethnic origin in relation to coronary heart disease risk factors in Adelaide schoolchildren. Med $\widetilde{f}$ Aust 1980; ii: risk fact 